Research paper

\title{
Mutations in two large pedigrees highlight the role of ZNF711 in X-linked intellectual disability
}

\author{
Ilse M. van der Werf a , Anke Van Dijck ${ }^{\mathrm{a}}$, Edwin Reyniers ${ }^{\mathrm{a}}$, Céline Helsmoortel ${ }^{\mathrm{a}}$, Ajay Anand Kumar ${ }^{\mathrm{a}}$, \\ Vera M. Kalscheuer ${ }^{b}$, Arjan PM de Brouwer ${ }^{c}$, Tjitske Kleefstra ${ }^{c}$, Hans van Bokhoven ${ }^{c}$, Geert Mortier ${ }^{a}$, \\ Sandra Janssens ${ }^{\mathrm{d}}$, Geert Vandeweyer ${ }^{\mathrm{a}}$, R. Frank Kooy ${ }^{\mathrm{a}, *}$ \\ a Department of Medical Genetics, University of Antwerp and University Hospital Antwerp, Antwerp, Belgium \\ ${ }^{\mathrm{b}}$ Research Group Development and Disease, Max Planck Institute for Molecular Genetics, Berlin, Germany \\ c Department of Human Genetics, Donders Institute for Brain, Cognition and Behaviour, Radboud University Medical Center, Nijmegen, The Netherlands \\ d Center for Medical Genetics Ghent, Ghent University, Ghent University Hospital, Ghent, Belgium
}

\section{A R T I C L E I N F O}

\section{Article history:}

Received 14 October 2016

Received in revised form 2 December 2016

Accepted 14 December 2016

Available online 16 December 2016

\section{Keywords:}

MRX65

XLID

ZNF711

\begin{abstract}
A B S T R A C T
Intellectual disability (ID) affects approximately $1-2 \%$ of the general population and is characterized by impaired cognitive abilities. ID is both clinically as well as genetically heterogeneous, up to 2000 genes are estimated to be involved in the emergence of the disease with various clinical presentations. For many genes, only a few patients have been reported and causality of some genes has been questioned upon the discovery of apparent loss-offunction mutations in healthy controls. Description of additional patients strengthens the evidence for the involvement of a gene in the disease and can clarify the clinical phenotype associated with mutations in a particular gene.

Here, we present two large four-generation families with a total of 11 males affected with ID caused by mutations in ZNF711, thereby expanding the total number of families with ID and a ZNF711 mutation to four. Patients with mutations in ZNF711 all present with mild to moderate ID and poor speech accompanied by additional features in some patients, including autistic features and mild facial dysmorphisms, suggesting that ZNF711 mutations cause non-syndromic ID.
\end{abstract}

@ 2016 Elsevier B.V. All rights reserved.
Abbreviations: ADID, autosomal dominant intellectual disability; ARID, autosomal recessive intellectual disability; CADD, Combined Annotation Dependent Depletion; cDNA, complementary deoxyribonucleic acid; DNA, deoxyribonucleic acid; ExAC, Exome Aggregation Consortium; GRCh37/hg19, human genome build 19; HEK293, human embryonic kidney cells 293; ICD-10, 10th revision of the International Statistical Classification of Diseases and Related Health Problems; ID, intellectual disability; IQ intelligence quotient; MRX65, mental retardation, X-linked 65; (q)PCR, (quantitative) polymerase chain reaction; REVEL, rare exome variant ensemble learner; RNA, ribonucleic acid; SNP, single nucleotide polymorphism; STR, short tandem repeat; TCGA, The Cancer Genome Atlas; UTR, untranslated region; XLID, X-linked intellectual disability; CAMKMT, calmodulin-lysine $\mathrm{N}$-methyltransferase; $C D C A 7$, cell division cycle associated 7; $C H D H$, choline dehydrogenase; CNN3, calponin 3; FYN, FYN protooncogene, Src family tyrosine kinase; HPRT1, hypoxanthine phosphoribosyltransferase 1 ; KDM5C, lysine demethylase 5C; LRRC4, leucine rich repeat containing 4; PHF8, PHD finger protein 8; PIEZO2, piezo type mechanosensitive ion channel component 2; $P Q B P 1$, polyglutamine binding protein 1; PTBP1, polypyrimidine tract binding protein $1 ;$ SYP, synaptophysin; TAF6, TATA-box binding protein associated factor 6; THY1, Thy-1 cell surface antigen; YWHAZ, tyrosine 3-monooxygenase/tryptophan 5-monooxygenase activation protein zeta; ZNF41, zinc finger protein 41 ; ZNF81, zinc finger protein 81 ; ZNF674, zinc finger protein 674; ZNF711, zinc finger protein 711 .

* Corresponding author at: Department of Medical Genetics, University of Antwerp, Prins Boudewijnlaan 43, 2650 Edegem, Belgium.

E-mail address: Frank.Kooy@uantwerpen.be (R.F. Kooy).

\section{Introduction}

\subsection{Intellectual disability}

Intellectual disability (ID) is defined by an IQ below 70 and problems in adaptive functioning that manifest before the age of 18 (ICD-10) and is present in around $1-2 \%$ of the population (Leonard and Wen, 2002). ID is both clinically and genetically very heterogeneous, which complicates the establishment of a genetic diagnosis. Multiple genetic causes of ID have been identified to date, including large chromosomal abnormalities (aneuploidies, translocations), deletions and duplications encompassing single exons up to multiple genes and point mutations affecting a single gene. ID is often caused by de novo mutations in sporadic cases, but can also be inherited in autosomal dominant (ADID), autosomal recessive (ARID) and X-linked manner (XLID). Until the recent development of next-generation sequencing techniques, the hereditary forms of ID were studied most extensively in large families that enabled linkage-based gene mapping. 


\subsection{X-linked intellectual disability}

Historically, X-linked forms of intellectual disability have been studied most extensively, notably because X-linked pedigrees may be large and have multiple affected members throughout different generations. This is due to the presence of usually unaffected female carriers of the disorder, making these families eligible for linkage analysis. Large pedigrees with autosomal recessive forms are rarer and autosomal dominant mutations are predominantly de novo in origin. Nevertheless, the identification of disease causing genes in large XLID families is not straightforward. Tarpey et al. (2009) studied 208 XLID families by sequencing most coding exons on the X chromosome, leading to the identification of nine novel disease genes. Mutations in these genes, along with mutations in known disease genes on the $\mathrm{X}$ chromosome, likely resolved the genetic cause of disease in $25 \%$ of the studied families. Hu et al. (2016) studied 405 XLID families using X-exome resequencing and targeted sequencing of coding regions of known XLID genes and found evidence for seven novel disease genes (Hu et al., 2009; Hu et al., 2016). Targeted resequencing of 107 XLID genes in 50 patients that were negative for chromosomal aberrations, Fragile-X syndrome and had a family history suggestive for XLID, resulted in a diagnostic yield of $26 \%$ (Tzschach et al., 2015). Thus, despite these apparent successes in gene-identification, the majority of mutations in XLID genes have been identified in a limited number of families only. Interestingly, at least $1 \%$ of the genes on the $\mathrm{X}$ chromosome can be affected by loss-offunction mutations without noticeable phenotypic consequences (Tarpey et al., 2009). These observations inspired Piton et al. (2013) to revisit all genes on the $\mathrm{X}$ chromosome previously reported as causal for ID. Their evaluation was based on multiple criteria, including the presence of truncating mutations in a control cohort and the scarcity of ID families with mutations affecting a postulated XLID gene. In the conclusions of their report, they challenge the causality of no less than ten reported XLID genes, including the zinc-finger genes ZNF41, ZNF81 and ZNF674. Taken together, these studies highlight the relevance of reporting novel mutations in potential XLID genes with limited support for causality.

\subsection{ZNF711}

One of the genes with limited evidence for causality is ZNF711, as hitherto only two truncating mutations in this gene have been reported in a single study (Tarpey et al., 2009). The exact function of ZNF711 has not been clarified yet, but many of the $\mathrm{Cys}_{2} \mathrm{His}_{2}$ zinc finger proteins function as a transcription factor by binding to specific DNA sequences. ZNF711 contains two Zfx/Zfy transcription activation regions and 12 $\mathrm{C} 2 \mathrm{H} 2$-like domains. Zfx/Zfy transcription activation regions are often found $\mathrm{N}$-terminal to multiple copies of a $\mathrm{C} 2 \mathrm{H} 2$ Zinc finger and have been shown to activate transcription (Mardon et al., 1990). C2H2 domains are classical zinc fingers, in which two cysteine and two histidine residues coordinate a zinc ion (Bohm et al., 1997; Marco et al., 2003).

Here, we present two large families with X-linked intellectual disability, in which we identified mutations in ZNF711.

\section{Patients and methods}

\subsection{Patients}

Families were ascertained from Belgium and the Netherlands. DNA was isolated from peripheral blood using standard methods. This study was approved by the Ethics Committee of the University Hospital Antwerp, Belgium and the Medical Ethical Committee Arnhem-Nijmegen, the Netherlands and adhered to the Declaration of Helsinki (7th revision, 2013). Written informed consent was obtained from each individual.

\subsection{Linkage analysis and genome-wide copy number analysis}

Linkage analysis of family A had been performed previously using 17 markers (DXS1060, DXS8051, DXS987, DXS1226, DXS1214, DXS1068, DXS993, DXS991, DXS986, DXS990, DXS1106, DXS8055, DXS1001, DXS1047, DXS1227, DXS8043, DXS1073) on 27 individuals (AI.1, AI.2, AII.1, AII.2, AII.4, AII.6, AII.7, AII.8, AII.10, AII.11, AIII.3, AIII.5, AIII.6, AII.9, AIII.12, AIII.14, AIII.15, AIII.16, AIII.18, AIII.19, AlII.20, AlII.21, AIII.22, AIV.9, AIV.10, AIV.12 and AIV.13). More recently, we obtained SNP array data using HumanCytoSNP-12 v2.1 beadchips scanned on an iScan system, following standard protocols as provided by the manufacturer (Illumina, San Diego, California, USA). X-linked recessive single point linkage analysis was performed using the MINX package of Merlin (v1.1.2) on SNP data of 12 family members (AII.2, AII.4, AII.8, AII.11, AIII.12, AIII.14, AIII.16, AIII.18, AIII.20, AIII.22, AIV.7 and AIV.13) (Abecasis et al., 2002). To define the parametric model, disease allele frequency was set to 0.0001 and penetrance to 0.0001 and 1.000 for male individuals carrying wild type or mutant alleles respectively. Analysis was performed on the X chromosome only and the intermarker distance used was $0.45 \mathrm{cM}$. In addition to the linkage analyses, we performed genome-wide copy number analysis on the same SNP array datasets, using the CNV-Webstore (Vandeweyer et al., 2011).

\subsection{Exome sequencing}

Exome sequencing was performed for individual AIV.13 using TruSeq DNA sample preparation (Illumina, San Diego, CA, USA) and SeqCap EZ Exome v3 enrichment (Roche, Basel, Switzerland) according to the standard protocols supplied by the manufacturers. Sequencing was performed on an Illumina HiSeq 1500 (Illumina, San Diego, CA, USA) using a $2 \times 100$ bp sequencing run. Data-analysis was done using an in-house pipeline as described before (Helsmoortel et al., 2015). Data filtering and annotation of variants in the linkage interval was performed with VariantDB (Vandeweyer et al., 2014b), using the settings as described before (Helsmoortel et al., 2015). A summary of the quality metrics for this sample has been included in supplementary Table 1.

Additional copy number analyses with higher resolution were performed based on the whole exome sequencing data. Starting from the BAM files from patient AIV.13 and one male control sample that was included in the same sequencing run and had similar coverage, the average per base coverage was calculated for each exon within the linked region using Bedtools (v2.17.0) (Quinlan and Hall, 2010). Exons with average coverage below $10 \times$ in either sample were excluded from the analysis. Log2 scaled ratios were computed using R (v3.2.3) for 3883 exons. The presence of CNVs was checked in the linked region by either visual inspection or by a sliding window approach. For the sliding window, thresholds were set to three consecutive exons with a deviation from zero of at least 3 times the standard deviation ( $s d=0.263$ ).

\subsection{Sanger confirmation}

Confirmation of the ZNF711 variants was performed using Sanger sequencing. Primer sequences and conditions for PCR are available upon request. PCR products were sequenced using the ABI PRISM BigDye Terminator Cycle Sequencing V2.0 Ready Reaction Kit and analyzed with the ABI PRISM 3730 or ABI3130XL Genetic Analyzer (Applied Biosystems, Foster City, USA). The identified variants have been entered into the ZNF711 LOVD database (http://databases.lovd.nl/shared/genes/ ZNF711) under individuals 00088189 (AIV.13) and 00088190 (BIV.1).

\subsection{Genome-wide expression arrays}

RNA was isolated from lymphoblastoid cell lines using Trizol Reagent (ThermoFisher Scientific, Waltham, MA, USA) according to the manufacturer's protocol for individuals AIII.18 and BIII.6. Potential 
residual DNA was depleted using the DNA-free DNA Removal Kit (ThermoFisher Scientific). RNA concentration and quality was assessed using both NanoDrop (ThermoFisher Scientific) and the Experion RNA Standard Sensitivity Analysis Kit (BioRad, Hercules, CA, USA). Sample preparation was done using the Illumina TotalPrep RNA Amplification Kit (ThermoFisher Scientific). Genome-wide expression was determined using HumanHT-12 v4 Expression BeadChips on an iScan system (Illumina, San Diego, CA, USA), according to the protocol supplied by the manufacturer. Data were analyzed in $\mathrm{R}$ (version 3.3.0), using the 'beadarray' and 'limma' packages. All data were normalized and probes with bad quality were filtered out. Genes were defined as differentially expressed when the adjusted p-value (FDR) was below 0.05 and the log Fold Change was smaller than -1.5 or larger than 1.5. Lists of differentially expressed genes were compared with a list of genes causative for neurodevelopmental disorders (Grozeva et al., 2015; Vissers et al., 2016).

\section{6. $q P C R$}

RNA was isolated and assessed as described in Section 2.5 for individuals AIII.18, AIV.13, BII.8 and BIII.6. cDNA synthesis was performed with the SuperScript III First-Strand Synthesis System, using the random hexamer protocol supplied by the manufacturer (ThermoFisher Scientific). Primers were designed using our in-house qPCR primer design tool (Iqbal et al., 2013). Quantitative PCR was performed using the qPCR Mastermix Plus for SYBR Green I - no ROX (Eurogentec, Liège, Belgium) according to the manufacturer's protocol, on a Lightcycler480 (Roche, Basel, Switzerland). Data analysis was performed using qbase + (Biogazelle, Ghent, Belgium). HPRT1 and YWHAZ were used as reference genes for normalization of the data, stability of the reference genes was checked with the qbase + software. The geNorm expression stability value of the reference genes $(M=0.163)$ and the coefficient of variation of the normalized reference gene relative quantities $(\mathrm{CV}=0.057)$ are both well below threshold settings ( 0.5 and 0.2 , respectively), indicating that the used reference genes are appropriate for normalization (Vandesompele et al., 2002; Hellemans et al., 2007).

\subsection{ZNF711 variants in ExAC database}

Variants in ZNF711 were retrieved from the ExAC database (Exome Aggregation Consortium (ExAC), Cambridge, MA (URL: http://exac. broadinstitute.org) [accessed 07/2016]). Variants were annotated with CADD scores (Kircher et al., 2014) and REVEL scores (Ioannidis et al., 2016) after which the list was filtered for annotation ( $3^{\prime}$ UTR, $5^{\prime}$ UTR, intronic and synonymous mutations were not considered) and only variants with a CADD-Phred score $>20$ were selected. Only variants found in hemizygous state were considered, as these could potentially evoke a phenotype in the males carrying them. ExAC datasets excluding the TCGA (The Cancer Genome Atlas) samples or the psychiatric cohort samples (53,105 and 45,376 samples remaining, respectively) were downloaded (ExAC database, release 0.3). Using ANNOVAR, variants present exclusively in the TCGA cohort or the psychiatric cohort were determined (Wang et al., 2010).

\section{Results}

\subsection{Clinical description patients family $A$}

Family $A$ is a four-generation family with five affected male individuals (Fig. 1). Affected individuals from family A are characterized by mild to moderate intellectual disability (5/5; Table 1$)$, motor delay (4/5) and poor speech (4/5). Two of them present with autistic features, being hand flapping and avoiding eye contact. Craniofacial features include a long face (4/5), synophris (3/5) and relatively large ears (4/5).

\subsubsection{Molecular diagnosis family $A$}

Affected males of family A were tested negative for the Fragile-X Syndrome repeat expansion. Linkage testing with STR marker analysis revealed a linked region on chrX: 31260748-102732317 (GRCh37/ hg19), delimited by STR markers DXS1214 and DXS1106. More recently, we performed linkage analysis using SNP markers on a subset of the family and confirmed the linkage interval. Copy number analysis did not reveal any deletions or duplications on chromosome $\mathrm{X}$ that could explain the phenotype of the patients. Higher resolution copy number analysis based on whole exome sequencing data confirmed the absence of exonic deletions and duplications in the linked region (Supplementary Fig. 1). Whole exome sequencing of individual AIV.13 resulted in five high quality variants within the linked region, of which three were known polymorphisms (rs2208592, rs144899652 and rs41297342). One variant (SYP, NM_003179.2:c.184G>C) was predicted to be a polymorphism by MutationTaster (Schwarz et al., 2014), with a CADDPhred score of 8.4 (Kircher et al., 2014). We also found a one base pair deletion in ZNF711 (NM_021998.4:c.2054del, p.(Phe685Serfs*7)), resulting in a frameshift with a premature stop codon (Fig. 2). This stop codon is located in the last exon of the gene and the resulting mRNA transcript is therefore predicted to escape from nonsense-mediated decay (Nagy and Maquat, 1998). The variant is predicted to be disease-causing by MutationTaster (Schwarz et al., 2014) and has a CADD_Phred score of 34 (Kircher et al., 2014). The variant has not been reported in ExAC. This frameshift variant fully segregated with the ID phenotype in the family (Fig. 1).

\subsection{Clinical description patients family $B$}

Family B has been described before as family MRX65 (Yntema et al., 1999). It is a family with six affected males in three generations (Fig. 1). They are characterized by mild to moderate intellectual disability (6/6; Table 1 ) and speech delay (6/6). Four out of five adults are obese. Craniofacial features include a broad face $(6 / 6)$ and a prominent forehead (3/6).

\subsubsection{Molecular diagnosis family $B$}

Linkage analysis mapped the underlying disease gene to the pericentromeric region of chromosome $\mathrm{X}$ with flanking markers DXS573 (Xp11.23, chrX:49138851-49138993 (GRCh37/hg19)) and DXS990 (Xq21.32, chrX:93000597-93000819 (GRCh37/hg19)) (Yntema et al., 1999). Massively parallel sequencing of all exons on the X chromosome revealed a potential pathogenic variant in ZNF711 (NM_021998.4:c.731T>C, p.Ile244Thr). This variant was identified in the family in a large screening study and is one of approximately 200 potentially damaging variants that were reported but not followed up in this study (Hu et al., 2016). The variant is predicted to be diseasecausing by MutationTaster (Schwarz et al., 2014), has a CADD_Phred score of 26.2 and is not reported in ExAC. The c.731T $>$ C variant is located in the previously determined linkage interval and fully segregates with the ID in the family (Figs. 1 and 2).

\subsection{ZNF711 variants in ExAC database}

A query on the ExAC database showed that no loss-of-function - being nonsense mutations or mutations disrupting a splice acceptor or donor site - or frameshift mutations are detected to date, suggesting that these type of mutations are very rare and likely detrimental. The ExAC database does contain 64 potentially damaging (CADD_Phred > 20) variants in ZNF711, including mainly missense variants but also one in-frame deletion and one mutation disrupting the start codon. None of these 64 variants were found in homozygous state, 29 of the variants have been detected in hemizygous state (Supplementary Table 2). Of these 29 variants, one variant was exclusively detected in the Cancer Genome Atlas (TCGA) cohort and three variants were detected solely in the psychiatric cohort. 

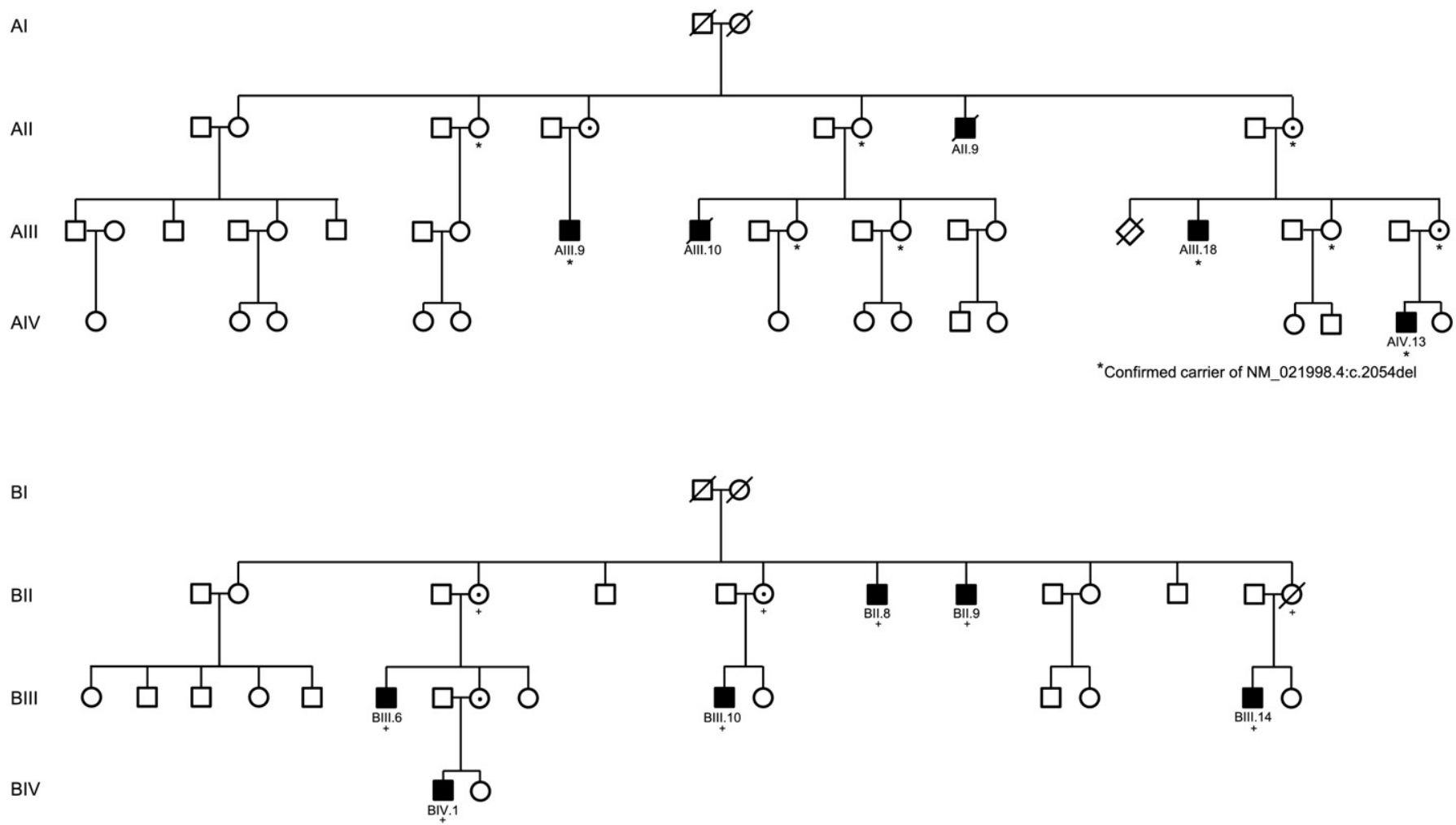

${ }^{+}$Confirmed carrier of NM_021998.4:c.731T >C

Fig. 1. Pedigrees of the studied families. Upper panel: pedigree family A. Lower panel: pedigree family B.

\subsection{Expression analysis}

We hypothesize that ZNF711 may act as a transcription factor and influences the expression levels of (several) target genes, based on its functional domains. Genome-wide expression profiles were determined for two patients (AIII.18 and BIII.6) and compared to the expression profiles of seven male controls to detect differential expression. Analysis of the results revealed 19 differentially expressed genes when comparing the two patients with all the controls. To validate these results, we used qPCR to compare the expression of these 19 genes in two patients from each family (AIII.18, AIV.13, BII.8 and BIII.6) with four controls. Expression levels of three genes appeared to be too low to reliably quantify with qPCR, suggesting that these signals on the expression array originated from noise. The differential expression remained significant ( $\mathrm{p}<0.05, t$-test) for five genes $(\mathrm{CHDH}$, CNN3, FYN, PIEZO2 and THY1) across all four patients (Table 2).

Following our genome-wide expression study, we investigated the expression levels of a few genes in more detail based on literature showing that ZNF711 and the histone demethylase PHF8 interact directly at the promotor region of several target genes (Kleine-Kohlbrecher et al.,

Table 1

Clinical overview of the patients.

\begin{tabular}{|c|c|c|c|c|c|c|c|c|c|c|c|c|}
\hline & AlI.9 $9^{\mathrm{a}}$ & AIII.9 & AIII.10 & AIII.18 & AIV.13 & BII.8 & BII.9 & BIII.6 & BIII.10 & BIII.14 & BIV.1 & Summary \\
\hline Gender & M & M & $\mathrm{M}$ & M & M & M & M & M & M & M & M & \\
\hline Age at last observation (y) & $\mathrm{U}$ & 53 & 17 & 35 & 13 & 56 & 53 & 52 & 24 & 28 & 6.5 & \\
\hline Birth weight (SD) & $U$ & +1 & $\mathrm{U}$ & +2.5 & +1 & $\mathrm{U}$ & $\mathrm{U}$ & $\mathrm{U}$ & $\mathrm{U}$ & $\mathrm{U}$ & $\mathrm{U}$ & \\
\hline Birth length (SD) & $\mathrm{U}$ & $\mathrm{U}$ & $\mathrm{U}$ & $\mathrm{U}$ & 0 & $\mathrm{U}$ & $\mathrm{U}$ & $\mathrm{U}$ & $\mathrm{U}$ & $\mathrm{U}$ & $\mathrm{U}$ & \\
\hline Head circumference at birth (SD) & $\mathrm{U}$ & $\mathrm{U}$ & $\mathrm{U}$ & $\mathrm{U}$ & +1 & $\mathrm{U}$ & $\mathrm{U}$ & $\mathrm{U}$ & $\mathrm{U}$ & $\mathrm{U}$ & $\mathrm{U}$ & \\
\hline Weight at last observation (SD) & $\mathrm{U}$ & +0.5 & 0 & +1 & +0.5 & +4 & +5 & +2.5 & -1.33 & +3 & -2 & \\
\hline Height at last observation (SD) & -0.5 & -3.25 & -1.5 & 0 & -1 & -1.25 & -2 & -1 & -3 & 0 & -3.5 & \\
\hline Head circumference at last observation (SD) & -0.5 & -0.5 & $\mathrm{U}$ & +0.5 & +1.25 & +0.63 & +1.25 & 0 & +0.63 & +1.5 & -2.5 & \\
\hline Intellectual disability ( + mild ID; ++ moderate ID) & ++ & + & + & + & ++ & + & ++ & ++ & ++ & + & + & $11 / 11$ \\
\hline Speech delay & + & - & + & + & + & + & + & + & + & + & + & $10 / 11$ \\
\hline Motor delay & + & + & - & + & + & $\mathrm{U}$ & $\mathrm{U}$ & $\mathrm{U}$ & $\mathrm{U}$ & $\mathrm{U}$ & $\mathrm{U}$ & $4 / 5$ \\
\hline Autistic features & $\mathrm{U}$ & $\mathrm{U}$ & $\mathrm{U}$ & + & + & $\mathrm{U}$ & $\mathrm{U}$ & $\mathrm{U}$ & $\mathrm{U}$ & $\mathrm{U}$ & $\mathrm{U}$ & $2 / 2$ \\
\hline Constipation & + & + & - & + & + & $\mathrm{U}$ & $\mathrm{U}$ & $\mathrm{U}$ & $\mathrm{U}$ & $\mathrm{U}$ & $\mathrm{U}$ & $4 / 5$ \\
\hline Long face & + & + & + & + & - & - & - & - & - & - & - & $4 / 11$ \\
\hline Broad face & - & - & - & - & + & + & + & + & + & + & + & $7 / 11$ \\
\hline Synophris & - & + & - & + & + & - & - & - & - & - & - & $3 / 11$ \\
\hline Prominent forehead & - & - & - & - & - & + & + & + & - & - & - & $3 / 11$ \\
\hline Broad nasal base & - & - & - & - & - & - & + & - & + & - & - & $2 / 11$ \\
\hline Broad nasal tip & - & - & - & - & + & + & - & - & + & - & + & $4 / 11$ \\
\hline Large ears & + & + & + & + & - & - & - & - & - & - & - & $4 / 11$ \\
\hline
\end{tabular}

$\mathrm{M}=$ male, $\mathrm{y}=$ year, $\mathrm{SD}=$ standard deviation, $\mathrm{U}=$ unknown.

a Deceased. 
Family A: c.2054del, p.(Phe685Serfs ${ }^{\star} 7$ )

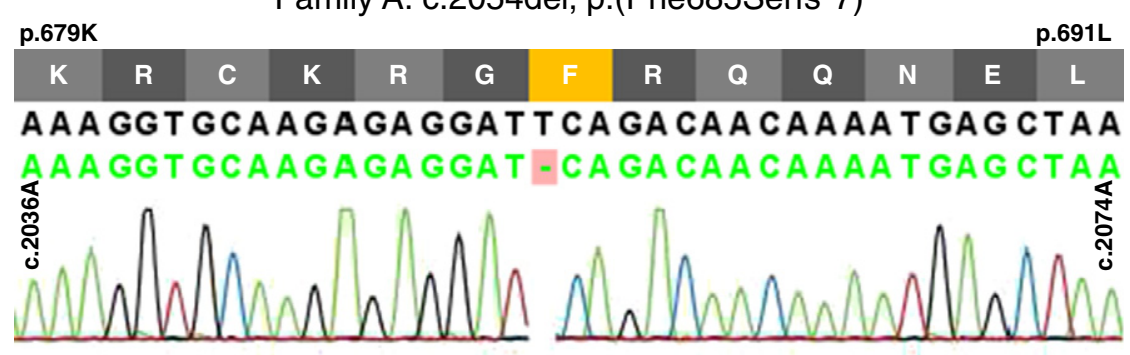

Family B: c.731T>C, p.(lle244Thr)

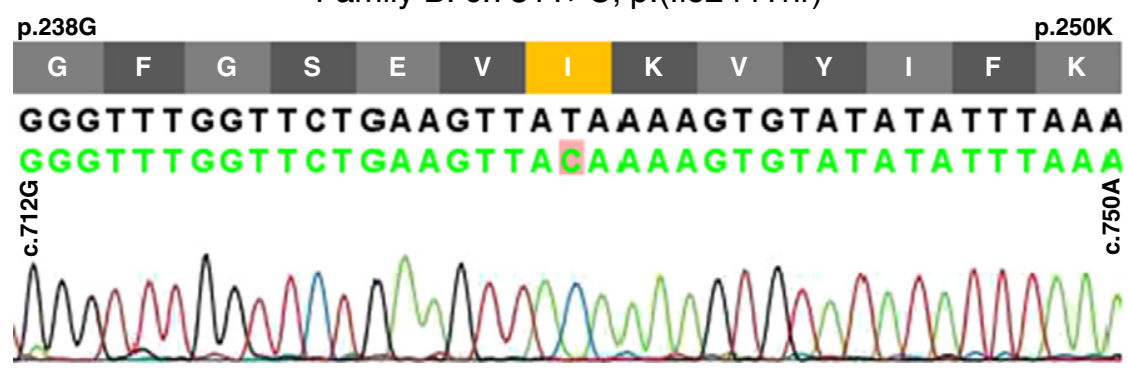

Fig. 2. Electropherograms of the mutations in ZNF711. Upper panel: mutation family A. Lower panel: mutation family B.

2010). Upon shRNA-mediated knockdown of ZNF711 or PHF8 in HEK293 cells, a total of eight genes were shown to be significantly underexpressed using qPCR (Kleine-Kohlbrecher et al., 2010). To determine whether mutations in ZNF711 could have the same effect, we performed qPCR for these eight genes (KDM5C, TAF6, CDCA7, CAMKMT, LRRC4, PTBP1, ZNF41 and $P Q B P 1$ ) as well as ZNF711 and PHF8 for two patients from each family (AIII.18, AIV.13, BII.8 and BIII.6). PHF8, CDCA7 and CAMKMT expression levels appeared to be too low in our lymphoblastoid cell lines to obtain reliable results and were therefore excluded from further analyses. Average expression per family was compared to expression of controls. Expression of ZNF41 was significantly higher in both family A and family B when compared to controls (two-sample $t$-test, $\mathrm{p}=0.0025$ and 0.021 respectively). Expression of $K D M 5 C$ was significantly lower in family $\mathrm{B}$ compared to controls $(\mathrm{p}=0.015)$. All other tested genes were not differentially expressed in the patients $(\mathrm{p}>0.05)$.

\section{Discussion}

ZNF711 has previously been linked to XLID (MRX97, OMIM \#300803), based on mutations identified in a large study by Tarpey et al. (2009). Mutations in this gene appear to be very rare, as none were reported in any of the recent large ID/ASD gene-identification studies (de Ligt et al., 2012; Rauch et al., 2012; De Rubeis et al., 2014; Iossifov et al., 2014). Here, we report two mutations in ZNF711 in 11 patients from two large families with an X-linked inheritance pattern of ID. Our study thus validates the

Table 2

Differentially expressed genes in individuals with ZNF711 mutations.

\begin{tabular}{llllll}
\hline Gene & Encoded protein & $\begin{array}{l}\text { Mean } \\
\text { controls }\end{array}$ & $\begin{array}{l}\text { Mean } \\
\text { patients }\end{array}$ & $\begin{array}{l}\text { Change in } \\
\text { patients (\%) }\end{array}$ & P-value \\
\hline CHDH & Choline dehydrogenase & 0.865 & 1.733 & +100.3 & 0.027 \\
CNN3 & Calponin 3 & 0.795 & 1.978 & +148.7 & 0.014 \\
FYN & $\begin{array}{l}\text { FYN proto-oncogene, Src } \\
\text { family tyrosine kinase }\end{array}$ & 1.498 & 0.435 & -71.0 & $<0.001$ \\
PIEZO2 & $\begin{array}{l}\text { Piezo type mechanosensitive } \\
\text { ion channel component 2 }\end{array}$ & 0.665 & 1.353 & +103.4 & 0.018 \\
THY1 & Thy-1 cell surface antigen & 0.748 & 1.943 & +159.9 & 0.018 \\
ZNF41 & Zinc finger protein 41 & 1.026 & 1.461 & +42.4 & 0.008 \\
\hline
\end{tabular}

Group means are the mean expression levels measured with qPCR, after normalization.

P-values are calculated using Welch two-sample $t$-tests. causality of ZNF711 mutations and categorizes it as an XLID gene beyond doubt, since four families have now been reported (Fig. 3).

The five affected males of family A share mild to moderate ID, motor delay and poor speech. Some of the affected family members display autistic features in addition. The six affected males of family B display mild to moderate ID with non-consistent facial features, such as a rather broad face and a prominent forehead. Patients from the two families with truncating mutations in ZNF711 described by Tarpey et al. displayed moderate intellectual disability without consistent additional features (Tarpey et al., 2009). Thus, mutations in ZNF711 appear to cause non-syndromic intellectual disability. Patients have mild to moderate ID with occasional non-consistent comorbidities, including autistic features and poor speech.

The ExAC database does not contain any loss-of-function mutations (premature stop, frameshift or splice site mutations) in ZNF711, strengthening the hypothesis that deleterious mutations in ZNF711 are causing disease. The database does encompass several missense variants and a start loss mutation. This latter mutation is reported only once, in a heterozygous female. A total of 29 potentially damaging mutations were present in hemizygous state, out of which three were exclusively found in the psychiatric subset of the ExAC cohort. We used CADD and REVEL, two scoring systems based on a combined analysis of different pathogenicity predictors, to evaluate these variants (Kircher et al., 2014; Ioannidis et al., 2016). We set the cut-offs at 20 for the CADD_Phred score (representing the top 1\% of variants most likely pathogenic) and 0.45 for REVEL (the tipping point from which variants with a higher score are more likely to be pathogenic than neutral). Only three ExAC variants passed both criteria, as did the mutation found in family B (Supplementary Table 2 and Supplementary Fig. 2). Since the disease phenotype caused by mutations in ZNF711 seems to be limited to ID with minor, non-consistent comorbidities, we cannot exclude that some of the potentially damaging variants in the control cohort might indeed cause (mild) ID in these individuals. In fact, variants in the Exome Sequencing Project (included in ExAC) that were predicted to be pathogenic have been identified in other known ID genes as well (Vandeweyer et al., 2014a).

In the study of Kleine-Kohlbrecher et al. (2010), multiple genes were found to be significantly underexpressed upon shRNA-mediated knockdown of ZNF711. In our patients, the expression of most of these genes did not deviate significantly from controls in lymphoblastoid cell lines. 

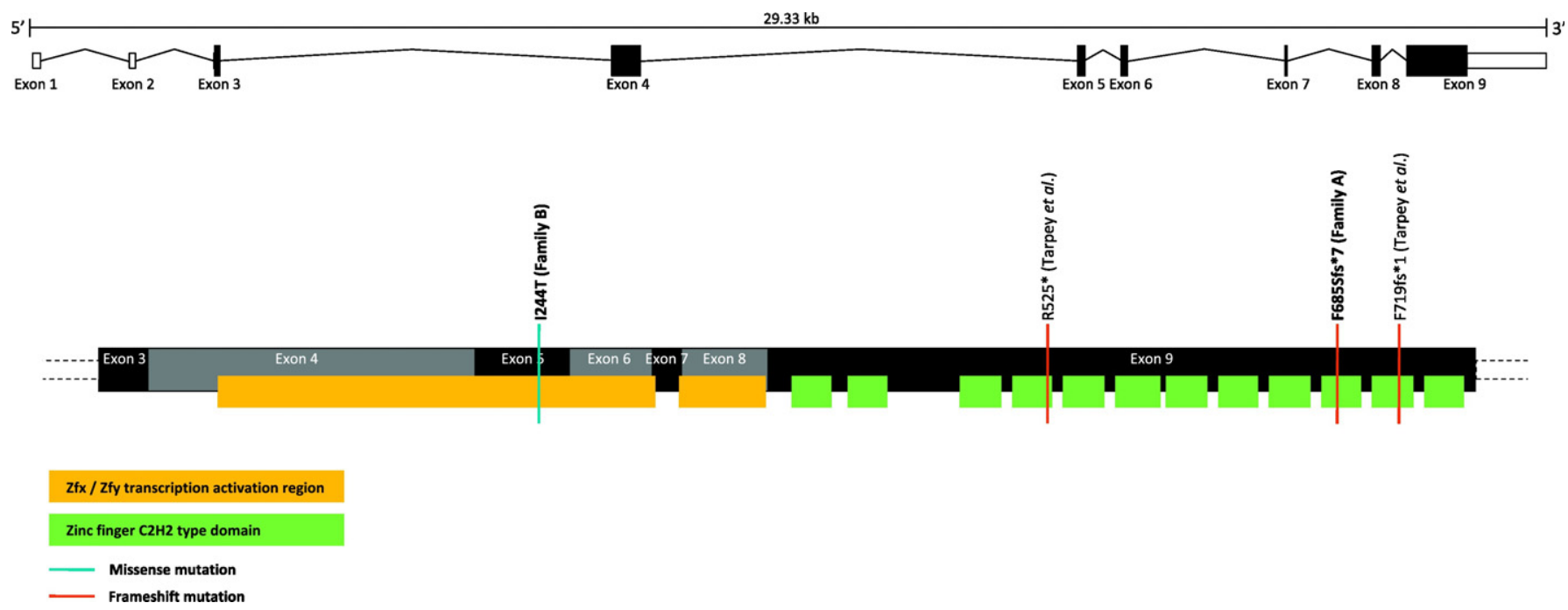

Fig. 3. Schematic overview of the ZNF711 gene with the positions of disease-causing mutations.

Only ZNF41 showed significant overexpression in the patients of both family $A$ and $B$, whereas $K D M 5 C$ was significantly underexpressed in family B, but not in family A. Thus, we did not replicate the results found in the study by Kleine-Kohlbrecher, which may be due to the fact that ZNF711 expression levels in our patients are normal and hence have a less severe impact than functional null mutations. This may also explain the fact that no ZNF711 premature termination codons resulting in nonsense-mediated mRNA decay have been reported thus far. Besides, the results of Kleine-Kohlbrecher et al. (2010) were obtained using HEK293 cells, whereas we tested expression in lymphoblastoid cell lines of patients. The discrepancy in obtained results between the two studies may therefore also be explained by the difference in tested cell line lineage.

Our genome-wide expression studies revealed only few differentially expressed genes in the patients compared to controls. Further validation experiments with qPCR including additional patients resulted in a total of five differentially expressed genes when comparing patients with mutations in ZNF711 with controls. Combined with the specifically screened genes from the Kleine-Kohlbrecher et al. (2010) study, we detected six genes (CHDH, CNN3, FYN, PIEZO2, THY1 and ZNF41) of which the expression is significantly altered in patients with ZNF711 mutations. $\mathrm{CHDH}$ has recently been described as a potential vulnerability gene for bipolar disorder, amongst other evidence based on the fact that $C H D H$ mRNA expression is consistently upregulated in the brains of bipolar disorder patients (Chang et al., 2016). In patients with ZNF711 mutations, we also observed a significant increase in expression levels of $\mathrm{CHDH}$ when compared to controls. Similarly, we found an upregulation of CNN3 expression in the ZNF711 patients. Significant upregulation of Calponin-3 was also found in the temporal cortices and cerebrospinal fluid of epilepsy patients when compared to non-epileptic controls (Han et al., 2012). In ZNF711 patients, the only significantly downregulated gene was FYN, encoding a nonreceptor protein tyrosine kinase expressed in neurons and glia (Bare et al., 1993). Fyn mutant mice display a reduction in long-term potentiation and impaired spatio-temporal learning, indicating a role for the Fyn protein in synaptic plasticity, which is a key process disturbed in patients with ID (Grant et al., 1992). Thus, aberrant expression levels of at least three out of six genes that were found deregulated by mutations in the putative transcription factor ZNF711, have been linked to phenotypes potentially related to the clinical presentation of patients carrying these mutations.

\section{Conclusion}

Here, we describe two mutations in ZNF711 and unequivocally place ZNF711 on the list of XLID genes. The causal mutation in family A is a single basepair deletion, resulting in a frameshift with a premature stop codon. In family B a missense mutation with predicted deleterious effect causes the phenotype. These mutations complement existing evidence establishing the role of ZNF711 in the emergence of ID. ZNF711 mutations do not seem to elicit a clinically recognizable ID syndrome. Affected individuals have mild to moderate ID with poor speech and inconsistent additional common comorbidities, including autistic features and mild facial dysmorphologies. Mutations in ZNF711 are accompanied by differential expression of six genes, that may be regulated directly or indirectly by ZNF711, which is predicted to be a transcription factor.

\section{Acknowledgements}

GV is a postdoctoral fellow of the Research Fund Flanders (FWO). Part of this work was financed by the EU FP7 project GENCODYS, grant number 241995 .

\section{Appendix A. Supplementary data}

Supplementary data to this article can be found online at http://dx. doi.org/10.1016/j.gene.2016.12.013.

\section{References}

Abecasis, G.R., Cherny, S.S., Cookson, W.O., Cardon, L.R., 2002. Merlin-rapid analysis of dense genetic maps using sparse gene flow trees. Nat. Genet. 30, 97-101.

Bare, D.J., Lauder, J.M., Wilkie, M.B., Maness, P.F., 1993. p59fyn in rat brain is localized in developing axonal tracts and subpopulations of adult neurons and glia. Oncogene 8, 1429-1436.

Bohm, S., Frishman, D., Mewes, H.W., 1997. Variations of the $\mathrm{C} 2 \mathrm{H} 2$ zinc finger motif in the yeast genome and classification of yeast zinc finger proteins. Nucleic Acids Res. 25, 2464-2469.

Chang, H., Li, L., Peng, T., Grigoroiu-Serbanescu, M., Bergen, S.E., Landen, M., Hultman, C.M., Forstner, A.J., Strohmaier, J., Hecker, J., Schulze, T.G., Muller-Myhsok, B., Reif, A., Mitchell, P.B., Martin, N.G., Cichon, S., Nothen, M.M., Jamain, S., Leboyer, M., Bellivier, F., Etain, B., Kahn, J.P., Henry, C., Rietschel, M., Swedish Bipolar Study, G, Moo, D.S.C., Xiao, X., Li, M., 2016. Identification of a Bipolar Disorder Vulnerable Gene CHDH at 3p21.1. Mol. Neurobiol.

de Ligt, J., Willemsen, M.H., van Bon, B.W., Kleefstra, T., Yntema, H.G., Kroes, T., Vulto-van Silfhout, A.T., Koolen, D.A., de Vries, P., Gilissen, C., del Rosario, M., Hoischen, A., Scheffer, H., de Vries, B.B., Brunner, H.G., Veltman, J.A., Vissers, L.E., 2012. Diagnostic exome sequencing in persons with severe intellectual disability. N. Engl. J. Med. 367, 1921-1929.

De Rubeis, S., He, X., Goldberg, A.P., Poultney, C.S., Samocha, K., Ercument Cicek, A., Kou, Y., Liu, L., Fromer, M., Walker, S., Singh, T., Klei, L., Kosmicki, J., Fu, S.C., Aleksic, B., Biscaldi, M., Bolton, P.F., Brownfeld, J.M., Cai, J., Campbell, N.G., Carracedo, A., Chahrour, M.H., Chiocchetti, A.G., Coon, H., Crawford, E.L., Crooks, L., Curran, S.R., Dawson, G., Duketis, E., Fernandez, B.A., Gallagher, L., Geller, E., Guter, S.J., Sean Hill, R., IonitaLaza, I., Jimenez Gonzalez, P., Kilpinen, H., Klauck, S.M., Kolevzon, A., Lee, I., Lei, J., Lehtimaki, T., Lin, C.F., Ma'ayan, A., Marshall, C.R., McInnes, A.L., Neale, B., Owen, 
M.J., Ozaki, N., Parellada, M., Parr, J.R., Purcell, S., Puura, K., Rajagopalan, D., Rehnstrom, K., Reichenberg, A., Sabo, A., Sachse, M., Sanders, S.J., Schafer, C., Schulte-Ruther, M., Skuse, D., Stevens, C., Szatmari, P., Tammimies, K., Valladares, O., Voran, A., Wang, L.S., Weiss, L.A., Jeremy Willsey, A., Yu, T.W., Yuen, R.K., Study, D.D.D, Homozygosity Mapping Collaborative for, A, Consortium, U.K, Autism Sequencing, C, Cook, E.H., Freitag, C.M., Gill, M., Hultman, C.M., Lehner, T., Palotie, A., Schellenberg, G.D., Sklar, P., State, M.W., Sutcliffe, J.S., Walsh, C.A., Scherer, S.W., Zwick, M.E., Barrett, J.C., Cutler, D.J., Roeder, K., Devlin, B., Daly, M.J., Buxbaum, J.D., 2014. Synaptic, transcriptional and chromatin genes disrupted in autism. Nature $515,209-215$.

Grant, S.G., O'Dell, T.J., Karl, K.A., Stein, P.L., Soriano, P., Kandel, E.R., 1992. Impaired longterm potentiation, spatial learning, and hippocampal development in fyn mutant mice. Science 258, 1903-1910.

Grozeva, D., Carss, K., Spasic-Boskovic, O., Tejada, M.I., Gecz, J., Shaw, M., Corbett, M., Haan, E., Thompson, E., Friend, K., Hussain, Z., Hackett, A., Field, M., Renieri, A., Stevenson, R. Schwartz, C., Floyd, J.A., Bentham, J., Cosgrove, C., Keavney, B., Bhattacharya, S., Italian, X.I.M.R.P, Consortium, U.K, Consortium, G, Hurles, M., Raymond, F.L., 2015. Targeted next-generation sequencing analysis of 1,000 individuals with intellectual disability. Hum. Mutat. 36, 1197-1204.

Han, Y., Yin, H., Xu, Y., Zhu, Q., Luo, J., Wang, X., Chen, G., 2012. Increased expression of calponin-3 in epileptic patients and experimental rats. Exp. Neurol. 233, 430-437.

Hellemans, J., Mortier, G., De Paepe, A., Speleman, F., Vandesompele, J., 2007. qBase relative quantification framework and software for management and automated analysis of real-time quantitative PCR data. Genome Biol. 8, R19.

Helsmoortel, C., Vandeweyer, G., Ordoukhanian, P., Van Nieuwerburgh, F., Van der Aa, N., Kooy, R.F., 2015. Challenges and opportunities in the investigation of unexplained intellectual disability using family-based whole-exome sequencing. Clin. Genet. 88, $140-148$.

Hu, H., Wrogemann, K., Kalscheuer, V., Tzschach, A., Richard, H., Haas, S.A., Menzel, C., Bienek, M., Froyen, G., Raynaud, M., Van Bokhoven, H., Chelly, J., Ropers, H., Chen, W., 2009. Mutation screening in 86 known X-linked mental retardation genes by droplet-based multiplex PCR and massive parallel sequencing. HUGO J. 3, 41-49.

Hu, H., Haas, S.A., Chelly, J., Van Esch, H., Raynaud, M., de Brouwer, A.P., Weinert, S., Froyen, G., Frints, S.G., Laumonnier, F., Zemojtel, T., Love, M.I., Richard, H., Emde, A.K., Bienek, M., Jensen, C., Hambrock, M., Fischer, U., Langnick, C., Feldkamp, M., Wissink-Lindhout, W., Lebrun, N., Castelnau, L., Rucci, J., Montjean, R., Dorseuil, O., Billuart, P., Stuhlmann, T., Shaw, M., Corbett, M.A., Gardner, A., Willis-Owen, S., Tan, C., Friend, K.L., Belet, S., van Roozendaal, K.E., Jimenez-Pocquet, M., Moizard, M.P., Ronce, N., Sun, R., O'Keeffe, S., Chenna, R., van Bommel, A., Goke, J., Hackett, A. Field, M., Christie, L., Boyle, J., Haan, E., Nelson, J., Turner, G., Baynam, G., GillessenKaesbach, G., Muller, U., Steinberger, D., Budny, B., Badura-Stronka, M., LatosBielenska, A., Ousager, L.B., Wieacker, P., Rodriguez Criado, G., Bondeson, M.L., Anneren, G., Dufke, A. Cohen, M. Van Maldergem, L., Vincent-Delorme, C., Echenne, B., Simon-Bouy, B., Kleefstra, T., Willemsen, M., Fryns, J.P., Devriendt, K., Ullmann, R., Vingron, M., Wrogemann, K., Wienker, T.F., Tzschach, A., van Bokhoven, H., Gecz, J., Jentsch, T.J., Chen, W., Ropers, H.H., Kalscheuer, V.M., 2016. X-exome sequencing of 405 unresolved families identifies seven novel intellectual disability genes. Mol. Psychiatry 21, 133-148.

Ioannidis, N.M., Rothstein, J.H., Pejaver, V., Middha, S., McDonnell, S.K., Baheti, S., Musolf, A., Li, Q., Holzinger, E., Karyadi, D., Cannon-Albright, L.A., Teerlink, C.C., Stanford, J.L. Isaacs, W.B., Xu, J., Cooney, K.A., Lange, E.M., Schleutker, J., Carpten, J.D., Powell, I.J. Cussenot, O., Cancel-Tassin, G., Giles, G.G., MacInnis, R.J., Maier, C., Hsieh, C.L., Wiklund, F., Catalona, W.J., Foulkes, W.D., Mandal, D., Eeles, R.A., Kote-Jarai, Z., Bustamante, C.D., Schaid, D.J., Hastie, T., Ostrander, E.A., Bailey-Wilson, J.E. Radivojac, P., Thibodeau, S.N., Whittemore, A.S., Sieh, W., 2016. REVEL: an ensemble method for predicting the pathogenicity of rare missense variants. Am. J. Hum. Genet. 99, 877.

Iossifov, I., O'Roak, B.J., Sanders, S.J., Ronemus, M., Krumm, N., Levy, D., Stessman, H.A., Witherspoon, K.T., Vives, L., Patterson, K.E., Smith, J.D., Paeper, B., Nickerson, D.A., Dea, J., Dong, S., Gonzalez, L.E., Mandell, J.D., Mane, S.M., Murtha, M.T., Sullivan, C.A., Walker, M.F., Waqar, Z., Wei, L., Willsey, A.J., Yamrom, B., Lee, Y.H., Grabowska, E., Dalkic, E., Wang, Z., Marks, S., Andrews, P., Leotta, A., Kendall, J., Hakker, I., Rosenbaum, J., Ma, B., Rodgers, L., Troge, J., Narzisi, G., Yoon, S., Schatz, M.C., Ye, K., McCombie, W.R., Shendure, J., Eichler, E.E., State, M.W., Wigler, M., 2014. The contribution of de novo coding mutations to autism spectrum disorder. Nature 515, 216-221.

Iqbal, Z., Vandeweyer, G., van der Voet, M., Waryah, A.M., Zahoor, M.Y., Besseling, J.A. Roca, L.T., Vulto-van Silfhout, A.T., Nijhof, B., Kramer, J.M., Van der Aa, N., Ansar, M. Peeters, H., Helsmoortel, C., Gilissen, C., Vissers, L.E., Veltman, J.A., de Brouwer, A.P., Frank Kooy, R., Riazuddin, S., Schenck, A., van Bokhoven, H., Rooms, L., 2013. Homozygous and heterozygous disruptions of ANK3: at the crossroads of neurodevelopmental and psychiatric disorders. Hum. Mol. Genet. 22, 1960-1970.

Kircher, M., Witten, D.M., Jain, P., O'Roak, B.J., Cooper, G.M., Shendure, J., 2014. A general framework for estimating the relative pathogenicity of human genetic variants. Nat. Genet. 46, 310-315.
Kleine-Kohlbrecher, D., Christensen, J., Vandamme, J., Abarrategui, I., Bak, M., Tommerup, N., Shi, X., Gozani, O., Rappsilber, J., Salcini, A.E., Helin, K., 2010. A functional link between the histone demethylase PHF8 and the transcription factor ZNF711 in X-linked mental retardation. Mol. Cell 38, 165-178.

Leonard, H., Wen, X., 2002. The epidemiology of mental retardation: challenges and opportunities in the new millennium. Ment. Retard. Dev. Disabil. Res. Rev. 8, 117-134.

Marco, E., Garcia-Nieto, R., Gago, F., 2003. Assessment by molecular dynamics simulations of the structural determinants of DNA-binding specificity for transcription factor Sp1. J. Mol. Biol. 328, 9-32.

Mardon, G., Luoh, S.W., Simpson, E.M., Gill, G., Brown, L.G., Page, D.C., 1990. Mouse Zfx protein is similar to Zfy-2: each contains an acidic activating domain and 13 zinc fingers. Mol. Cell. Biol. 10, 681-688.

Nagy, E., Maquat, L.E., 1998. A rule for termination-codon position within intron-containing genes: when nonsense affects RNA abundance. Trends Biochem. Sci. 23, 198-199.

Piton, A., Redin, C., Mandel, J.L., 2013. XLID-causing mutations and associated genes challenged in light of data from large-scale human exome sequencing. Am. J. Hum. Genet. 93, 368-383.

Quinlan, A.R., Hall, I.M., 2010. BEDTools: a flexible suite of utilities for comparing genomic features. Bioinformatics 26, 841-842.

Rauch, A., Wieczorek, D., Graf, E., Wieland, T., Endele, S., Schwarzmayr, T., Albrecht, B., Bartholdi, D., Beygo, J., Di Donato, N., Dufke, A., Cremer, K., Hempel, M., Horn, D. Hoyer, J., Joset, P., Ropke, A., Moog, U., Riess, A., Thiel, C.T., Tzschach, A., Wiesener, A., Wohlleber, E., Zweier, C., Ekici, A.B., Zink, A.M., Rump, A., Meisinger, C., Grallert, H., Sticht, H., Schenck, A., Engels, H., Rappold, G., Schrock, E., Wieacker, P., Riess, O. Meitinger, T., Reis, A., Strom, T.M., 2012. Range of genetic mutations associated with severe non-syndromic sporadic intellectual disability: an exome sequencing study. Lancet 380, 1674-1682.

Schwarz, J.M., Cooper, D.N., Schuelke, M., Seelow, D., 2014. MutationTaster2: mutation prediction for the deep-sequencing age. Nat. Methods 11, 361-362.

Tarpey, P.S., Smith, R., Pleasance, E., Whibley, A., Edkins, S., Hardy, C., O'Meara, S., Latimer C., Dicks, E., Menzies, A., Stephens, P., Blow, M., Greenman, C., Xue, Y., Tyler-Smith, C., Thompson, D., Gray, K., Andrews, J., Barthorpe, S., Buck, G., Cole, J., Dunmore, R., Jones, D., Maddison, M., Mironenko, T., Turner, R., Turrell, K., Varian, J., West, S., Widaa, S., Wray, P., Teague, J., Butler, A., Jenkinson, A., Jia, M., Richardson, D., Shepherd, R., Wooster, R., Tejada, M.I., Martinez, F., Carvill, G., Goliath, R., de Brouwer, A.P.M., van Bokhoven, H., Van Esch, H., Chelly, J., Raynaud, M., Ropers, H.-H., Abidi, F.E., Srivastava, A.K., Cox, J., Luo, Y., Mallya, U., Moon, J., Parnau, J., Mohammed, S., Tolmie, J.L., Shoubridge, C., Corbett, M., Gardner, A., Haan, E., Rujirabanjerd, S. Shaw, M., Vandeleur, L., Fullston, T., Easton, D.F., Boyle, J., Partington, M., Hackett, A., Field, M., Skinner, C., Stevenson, R.E., Bobrow, M.. Turner, G., Schwartz, C.E., Gecz, J., Raymond, F.L., Futreal, P.A., Stratton, M.R., 2009. A systematic, large-scale resequencing screen of X-chromosome coding exons in mental retardation. Nat. Genet. 41, 535-543.

Tzschach, A., Grasshoff, U., Beck-Woedl, S., Dufke, C., Bauer, C., Kehrer, M., Evers, C., Moog U., Oehl-Jaschkowitz, B., Di Donato, N., Maiwald, R., Jung, C., Kuechler, A., Schulz, S., Meinecke, P., Spranger, S., Kohlhase, J., Seidel, J., Reif, S., Rieger, M., Riess, A., Sturm, M., Bickmann, J. Schroeder, C., Dufke, A., Riess, O.., Bauer, P.., 2015. Next-generation sequencing in X-linked intellectual disability. Eur. J. Hum. Genet. 23, 1513-1518.

Vandesompele, J., De Preter, K., Pattyn, F., Poppe, B., Van Roy, N., De Paepe, A., Speleman, F., 2002. Accurate normalization of real-time quantitative RT-PCR data by geometric averaging of multiple internal control genes. Genome Biol. 3, 34.1-34.11.

Vandeweyer, G., Reyniers, E., Wuyts, W., Rooms, L., Kooy, R.F., 2011. CNV-WebStore: online CNV analysis, storage and interpretation. BMC Bioinforma. 12, 4.

Vandeweyer, G., Helsmoortel, C., Van Dijck, A., Vulto-van Silfhout, A.T., Coe, B.P., Bernier, R., Gerdts, J., Rooms, L., van den Ende, J., Bakshi, M., Wilson, M., Nordgren, A., Hendon, L.G., Abdulrahman, O.A., Romano, C., De Vries, B.B.A., Kleefstra, T., Eichler, E.E., Van der Aa, N., Kooy, R.F., 2014a. The transcriptional regulator ADNP links the BAF (SWI/SNF) complexes with autism. Am. J. Med. Genet. C 166, 315-326.

Vandeweyer, G., Van Laer, L., Loeys, B., Van den Bulcke, T., Kooy, R.F., 2014b. VariantDB: a flexible annotation and filtering portal for next generation sequencing data. Genome Med. 6, 74.

Vissers, L.E., Gilissen, C., Veltman, J.A., 2016. Genetic studies in intellectual disability and related disorders. Nat. Rev. Genet. 17, 9-18.

Wang, K., Li, M., Hakonarson, H., 2010. ANNOVAR: functional annotation of genetic variants from high-throughput sequencing data. Nucleic Acids Res. 38, e164.

World Medical Association Declaration of Helsinki, 2013. Ethical principles for medical research involving human subjects. JAMA 310 (20):2191-2194. http://dx.doi.org/10. 1001/jama.2013.281053 (Nov 27).

Yntema, H.G., van den Helm, B., Knoers, N.V., Smits, A.P., van Roosmalen, T., Smeets, D.F., Mariman, E.C., van der Burgt, I., van Bokhoven, H., Ropers, H.H., Kremer, H., Hamel, B.C., 1999. X-linked mental retardation: evidence for a recent mutation in a five-generation family (MRX65) linked to the pericentromeric region. Am. J. Med. Genet. 85, 305-308. 